\title{
Response of international shipping to the current environmental challenges
}

\author{
Marzenna Popek ${ }^{1, a}$ \\ ${ }^{1}$ Gdynia Maritime University, Department of Chemistry and Industrial Commodity, Gdynia, Poland
}

\begin{abstract}
The international shipping industry directly facilitates the growth of the world trade, economic development and improvement of the global living standards. As the world economy and population continue to expand, the volume of maritime trade is expected to increase significantly as well. Maritime transport already contributes significantly to the three pillars of sustainable development - social, environmental and economic. Maritime transportation is generally considered environmental friendly when compared to other transportation means, especially if the energy efficiency is measured per tonne transported/per mile. Nevertheless, emissions from the growing maritime transport sector represent a significant and growing source of air pollution. One of future goals in international shipping is to reduce $\mathrm{CO}_{2}$ emissions. The International Maritime Organization is the United agency responsible for the protection of the environment from the impact of maritime transport. All parts of shipping industry are examining a number of ways to reduce $\mathrm{CO}_{2}$ emissions, which are primarily linked to reducing fuel consumption. The paper identifies the main areas that should be addressed if maritime sustainable development is to be achieved. It presents analysis of activities focused on environmentally friendly solutions as a form of IMO support for realization of the strategy of sustainable development.
\end{abstract}

\section{Air pollution from ships}

The most important sector of the maritime industry is shipping. The international shipping industry is responsible for carriage of about $90 \%$ of world trade and is vital to the global economy. Without intercontinental shipping, the bulk trade of raw materials, fuel, affordable food and goods would simply not be possible. Low cost and efficiency of maritime transport has enabled the major shift towards industrial production in Asia.

The World trade is carried across the world's oceans by 90000 marine vessels. Maritime transport has been and still remains to be a very important catalyst of economic development and economic progress of all costal states. The water transport in the EU's directly employs about 200 thousand people, of which approximately $80 \%$ work in shipping and $20 \%$ in inland waterway transport. Globally, the sea transport industry directly employs about 1,5 million people (the crew). In the past three decades, volume of sea transportation grew by about $3,1 \%$ per year. Analysis of the volume of freight in maritime transport indicates that it is strictly dependent on the state of the global economy [1]. Global reduction in the gross world product and decrease in the trade in goods drastically affected the value of maritime transport. Positive macroeconomic phenomena have a direct impact on the state of maritime transport and structure. Demand for maritime transport services and seaborne trade volumes continues to be shaped by global economic growth and the need to carry merchandise trade.

An important factor determining the state of the maritime industry is the structure of maritime transport.

Greenhouse gases absorb and emit radiation into the atmosphere, which then influences the average temperature of the earth. Carbon dioxide is the most important greenhouse gas emitted by humans, but several other gases contribute to climate change, too.

Maritime transportation is generally considered environmental friendly when compared to other transportation means, especially if the energy efficiency is measured per tonne transported/per mile. Nevertheless, emissions from the growing maritime transport sector represent a significant and growing source of air pollution.

The fuel consumption od shipping is dominated by three types of ships: oil tankers, container ships and bulk cariers. There are the three most significant sectors of shipping industry from a $\mathrm{CO}_{2}$ perspective.

For the year 2012, total shipping emissions were approximately 938 million ton. International shipping emitted 769 million tonnes of $\mathrm{CO}_{2}$ in 2012, that is about $2,2 \%$ of the total global $\mathrm{CO}_{2}$ emissions. By contrast, in 2007, before the global economic downturn, international shipping is estimated to have emitted 885 million tonnes of $\mathrm{CO}_{2}$, that is $2,8 \%$ of the total global $\mathrm{CO}_{2}$ emissions $[2,3]$.

\footnotetext{
a Corresponding author:m.popek@wpit.am.gdynia.pl
} 
The contribution of global carbon dioxide emission from various sources is shown in Fig.1.

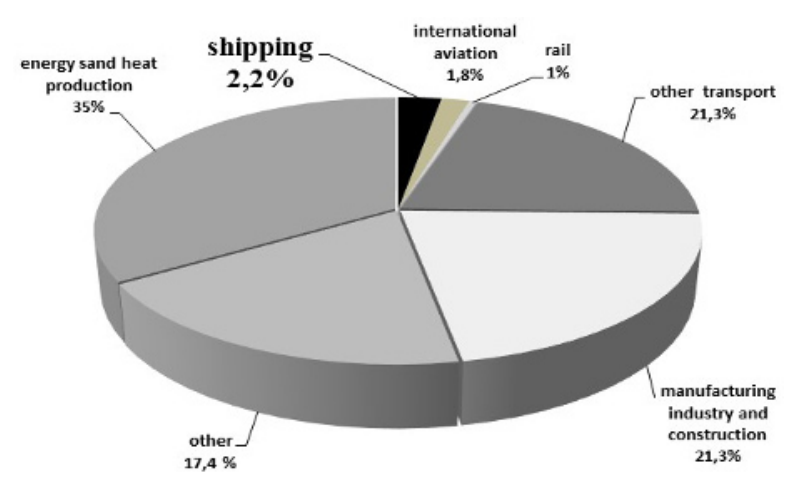

Figure 1. Shipping contribution to global $\mathrm{CO}_{2}$ emissions Source : [4]

Exhaust gases are the primary source of emissions from ships. Carbon dioxide is the most important GHG emitted by ships, both in terms of quantity and of global warming potential, other GHG emissions from ships are less important. $\mathrm{CO}_{2}$ emissions depend on the type of fuel, so the amount of carbon per unit of energy produced.

If international voyages were treated as a country, it would be the sixth largest producer of greenhouse gases. Only the United States, China, Russia, India and Japan emit more carbon dioxide than the world fleet. However, international shipping is the most energy efficient mode of transport and only a modest contributor to the overall emissions of $\mathrm{CO}_{2}$. During transport of one tonne of freight, the largest emissions of carbon dioxide come from air transport, and the minimum during operation of the largest ships [5].

Nevertheless, a global approach is to improve its energy efficiency and effective emissions control as sea transport will continue growing apace with the world trade.

Forecast scenarios for the medium term suggest that international shipping carbon emissions could increase by $50-250 \%$ by 2050 , depending on the expected long term growth of the world economy, population and global energy demand [1].

In addition to carbon dioxide, vessels release other materials such as $\mathrm{SOx}, \mathrm{NO}_{\mathrm{x}}$, ODS (ozone depleting substances), VOC (volatile organic compounds) and shipboard incineration, which also contributes to the environmental pollution, but both are less important in terms of quantity and potential of their emissions enhancing global warming.

Another product of fuel combustion is black carbon small very dark particles, which might warm the atmosphere about one third as much as $\mathrm{CO}_{2}$ [6]. Because black carbon absorbs much more light than it reflects, it warms the atmosphere through its interaction with sunlight. Black carbon is emitted in a variety of combustion processes and influences the Earth's climate. It has effects on clouds processes, solar radiation, and alters the melting of snow and ice cover. Marine Environment Protection Committee approved the Bond et al definition of 'Black Carbon' for international shipping as follows:
Black Carbon is a distinct type of carbonaceous material, formed only in flames during combustion of carbonbased fuels. It is distinguishable from other forms of carbon and carbon compounds contained in atmospheric aerosol because it has a unique combination of physical properties [7].

Although industrial activities are significant sources of black carbon, shipping emissions still represent minor contributions to overall emissions on the global scale. Emission rate of black carbon depends on the combustion process which is influenced by: fuel composition, flame temperature, type of engine, installation upgrades, and fuel and air mix ratio during combustion.

\section{Maritime sustainable development}

The continuous increase in the number of vessels and their exploitation result in reduced natural resources, in particular crude oil. Pollution from the combustion of fossil fuels contributes to the destruction of the ecosystem and threatens human health.

Shipping is subject to the first ever global and legally binding $\mathrm{CO}_{2}$ regulations for an entire economic or industrial sector.

Maritime transport already contributes significantly to the three pillars of sustainable development-social, environmental and economic.

Fundamental assumption of the sustainable marine transport may be formulated as follows:

Sustainable marine transport is a transportation system which provides secure, efficient and reliable transport of goods; support global safety and environmental standards, ensures appropriate education and training of crews.

A sustainable marine transport requires coordination at international level. International Maritime Organization (IMO) is a specialized agency of the United Nations, which developing and adopting global standard for the safety, efficiency, security of ships and protection of the environment from shipping operations. Its main role is to create a regulatory framework for the shipping industry. Through IMO, shipping industry works to ensure a continued contribution towards a green economy and sustainable growth. Its achieved through: implementation of global standards, increase of energy efficiency, promotion of new technology for safety, support in education and training, improved maritime security, enhancement of maritime traffic management and improvement of maritime infrastructure.

IMO's original mandate was principally concerned with maritime safety. The Organization assumed responsibility for pollution issues and subsequently has, over many years, adopted a wide range of measures to prevent and control pollution caused by ships and to mitigate the effects of any damage that may occur as a result of maritime operations and accidents.

Of the 51 treaty instruments for the regulation of international shipping IMO has adopted so far. The most important of them concerning the safety of life at sea and the protection of environment. They apply to $99 \%$ of the world's merchant fleet. 
In 1973 IMO established its Marine Environment Protection Committee (MEPC). MEPC gives extensive consideration to control of GHG emission from ships that contributes to the overall air quality problems encountered by population in many areas, and also affects the environment.

The original focus of its work was the prevention of marine pollution by oil, resulting in the adoption of the first ever comprehensive antipollution convention, the International Convention for the Prevention of Pollution from Ships (MARPOL) in 1973. MARPOL Convention is focused primarily on determining and developing a legal framework for the protection of marine environment and reduction of sea damages.

This has changed over the last few decades to include a much wider range of measures to prevent marine pollution, and the original MARPOL Convention was amended many times to also include requirements addressing pollution from chemicals, other harmful substances, garbage and sewage.

In 1997 the new Annex VI (Prevention of Air Pollution from Ships) of MARPOL Convention was adopted. The regulation seeks to minimize emission of greenhouse gases (GHG) and other relevant substances from ships which contributes to global air pollution.

\section{Reduction of emission $\mathrm{CO}_{2}$ and other relevant gases}

Emissions of carbon dioxide derived from ocean vessels, are currently unregulated - the United Nations Framework Convention on Climate Change (UNFCCC), concerning the general obligation of governments to reduce greenhouse gas emissions cannot be applied.

According to the Kyoto Protocol, $\mathrm{CO}_{2}$ emissions from international shipping cannot be attributed to any particular national economy due to its global nature and complex operations. A ship may be registered in one country while the beneficial owner of the ship may be located in another. Furthermore, the cargo carried by the ship will be of economic benefit to a number of different nations.

Kyoto Protocol principle "Common but Differentiated Responsibility" (CBDR) cannot be practically used for shipping without the danger of the significant ,carbon leakage."

Most shipping companies have the freedom to decide to register their ships with the "flag state". Only about $35 \%$ of world merchant fleet is registered in Kyoto Annex I countries. The application of CBDR would cause a reduction in the efficiency of maritime transport and the smooth flow of world trade.

Multilateral action is the most appropriate way to address emissions from the maritime transport sector. The IMO principle "no more favourable treatment" ensures that requirements adopted for shipping will be applied equally throughout the world, providing maximum environmental improvement. Failure to develop a global $\mathrm{CO}_{2}$ reduction regime for international shipping may greatly reduce the ability of the shipping as a whole to reduce its emissions.
Global shipping industry is of the opinion that it is possible for shipping to reduce $\mathrm{CO}_{2}$ emission through a combination of technological developments, building of new and bigger ships, use of new sources of fuel, introduction of the Energy Efficiency Design Index and Ship Energy Efficiency Management Plan (fig. 2.).

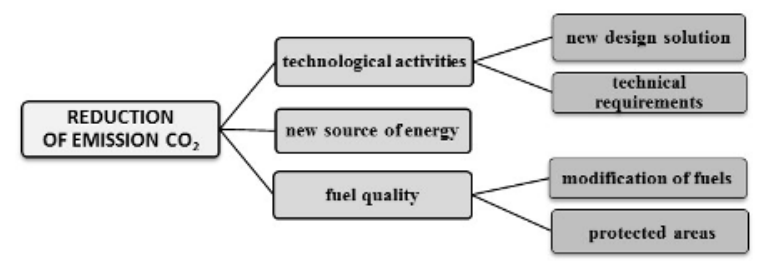

Figure 2. Measures to reduction $\mathrm{CO}_{2}$

Based on the approved programs and legislative changes the forecast reduction in $\mathrm{CO}_{2}$ emissions to 2050 is expected. The technical and operational measures will not be sufficient to satisfactorily reduce the amount of GHG emissions from international shipping. Therefore, Market-Based Measures have also been considered

\subsection{Technological activities}

Gases The various parts of shipping industry are examined a number of ways to reduce $\mathrm{CO}_{2}$ emissions, which are primarily linked to the reduction of fuel consumption, because bunker cost represents an increasingly significant proportion of ship's operational expenses.

In July 2011 IMO Members agreed to a package of technical requirements for reduction of $\mathrm{CO}_{2}$ emissions which entered into the force in January 2013. The new rules have been concluded in Annex VI of MARPOL Convention. The amendments include: a system of Energy Efficiency Design Indexing for new ships (EEDI) and Ship Efficiency Management Plan (SEEMP).

The EEDI system calculates vessel's energy efficiency based on ship's emissions, its capacity and its speed. EEDI system was developed for the largest and most energy consuming sectors of the world merchant fleet, because $70 \%$ of emissions come from oil tankers and gas carriers, bulk carriers, general cargo ships and container ships.

The base parameters (reductions) taken into account for calculation of EEDI are: lowering of ship speed, use of higher efficiency, derating of engines, use of LPG or LNG, optimisation of the hull and propeller, and coating.

One of the major parameters is the new design of the ship and its propeller.

Ship's lifetime very often exceeds thirty years, and the operating and business environment may change significantly in the course of the time. Better planning at the design stage may lead to a higher potential for reduction of emissions. Optimization of the hull, 
which is applied to new ship design, is focused on reducing resistance and wetted surface area.

Although the shipping industry is already energy efficient, additional improvements to hull, engine and propeller design are expected to produce further reduction in fuel consumption.

The environmental effect of EEDI is limited, since the requirements apply to new ships, where "new ship" means a vessel: the construction of which started in 2013 or was put into service after 1 July 2015.

SEEMP determines the way which allows companies to monitor and improve performance with regard to various factors that contribute to $\mathrm{CO}_{2}$ emissions. These include: optimising engine power, speed management, use of certain type of fuel, hull management, voyage planning and weather routeing.

Energy efficiency can be improved by using large ships, because it tends to reduce energy consumption. Reduction in speed will increase efficiency, but can be expensive, since they directly affect the number of the ships (more ships will be needed). Traffic management and control system play a role in reducing time in port through more efficient cargo handling.

Optimization and improvement of operational efficiency requires cooperation of several parties. Voyage optimization is the optimization of ship operation, which includes: selection of routes with respect to weather; just -in-time arrival, avoiding unnecessary ballast and trim optimization.

By avoiding unnecessary consumption of energy and parallel operation of electrical generators; optimization of steam plant, fuel clarifier and operation on board; and detection of leaking steam it is possible to reduce energy consumption on board.

Based on the approved programs and legislative changes, the forecast predicts reduction in $\mathrm{CO}_{2}$ emissions to 2050 , due to the use of technological innovations and changes in the operational process is presented in Table 1. The following changes in $\mathrm{CO}_{2}$ emission are expected: by changes in the design of 10 to $50 \%$, and changes in the operation of 10 to $50 \%$. In total, it is estimated that these changes may result in a reduction of greenhouse gas emissions from $25 \%$ to $75 \%$.

Table 1. Assessment of potential reduction of $\mathrm{CO}_{2}$ emission from shipping

\begin{tabular}{|l|c|}
\hline & Saving of $\mathbf{C O}_{2} /$ tonne-mille \\
\hline DESIGN (new ships): & $2 \div 50 \%$ \\
Concept, speed, capability & $2 \div 20 \%$ \\
Hull and superstructure & $5 \div 15 \%$ \\
Power and propulsion system & $5 \div 15 \%$ \\
Low-carbon fuel & $1 \div 10 \%$ \\
Renewable energy & $0 \%$ \\
Exhaust gas $\mathrm{CO}_{2}$ reduction & $5 \div 50 \%$ \\
\hline OPERATION (all ships) & $1 \div 10 \%$ \\
Flat management, logistics & $1 \div 10 \%$ \\
Voyage optimization & \\
Energy management & \\
\hline Sorce: [8]
\end{tabular}

Source: [8]

\subsection{Fuel quality}

IMO recognises that some areas need additional protection and MARPOL Convention defines certain areas as "Special Areas" (SA). There are areas characterised by heavy maritime traffic and low water exchange caused by the land-locked nature. For a technical reason relating to their oceanographical and ecological conditions, the adoption of special mandatory methods for the prevention of sea pollution is required. These special areas are provided with a higher level of protection than other areas on the sea. The special areas established under Annex V are: the Mediterranean Sea, the Baltic Sea Area, the Black Sea Area, the Gulfs area, the North Sea, the Wider Caribbean Region and Antarctic Area.

In addition, IMO identified "Particularly Sensitive Sea Areas" (PSSA) as the areas that need special protection because of their significance for recognized ecological, economic, social or scientific reasons and which may be exposed to damage by maritime activities. The criteria for identification of particularly sensitive sea areas and for the designation of special areas are not mutually exclusive. In many cases PSSA may be identified within a SA and vice versa.

The IMO Guidelines include criteria to allow areas to be designated a PSSA such as: ecological criteria; unique or rare system; diversity of system or vulnerability to degradation by natural events or human activities; social, cultural and economic criteria; significance of the area for tourism; scientific and educational criteria. When an area is approved as a PSSA, specific measures are used to control the maritime activities in that areas, such as routeing measures and strict application.

Under the MARPOL Convention, the rules, which seek to reduce $\mathrm{NO}_{\mathrm{X}}$ and $\mathrm{SO}_{\mathrm{X}}$ were adopted and emission control areas were established

SOx controls apply to all fuel combustion equipment and devices on-board ships. The SOx emission control areas (ECA) are: Baltic Sea, North Sea, the North American Area and United States Caribbean Sea Areas. The regulation limits the maximum sulphur content of the fuel used and has two stringency levels: one stringency level that holds in $\mathrm{SO}_{\mathrm{x}}$ emission control areas and, another less stringent level for outside ECAs as global requirement (Table 2).

Ships trading in designated emission control areas has to use fuel oil on board with a sulphur content of no more than $0,1 \%$ from 1 January 2015.

Table 2. IMO sulphur requirements

\begin{tabular}{|c|c|}
\hline $\begin{array}{c}\text { Outside ECA } \\
\text { (global requirement) }\end{array}$ & Inside ECA \\
\hline $\begin{array}{c}4,5 \% \text { prior to } 1 \text { January } \\
2012\end{array}$ & $1,5 \%$ prior to 1 July 2010 \\
\hline $\begin{array}{c}3,5 \% \text { on and after } 1 \\
\text { January } 2012\end{array}$ & $1,0 \%$ on and after 1 July \\
2010 \\
\hline $\begin{array}{c}0,5 \% \text { on and after } 1 \\
\text { January } 2020\end{array}$ & $0,1 \%$ on and after 1 January \\
2015
\end{tabular}

Source: [9] 
As a consequence of the new regulation, ships have started to use low sulphur fuel oil. An increasing number of ships uses as a fuel gas or fuel with low flashpoint. The severe limits concerning the sulphur content of marine fuels will definitely increase of cost of shipping. The derivative effect of the changes could result in a limitation of the competitiveness of the Polish and European economy. Implementation of the regulation will push up the freight rates. Higher ships cost will cause redefinition of cargo flow.

Annex VI of MARPOL Convention introduces a stepwise approach to the reduction of emission $\mathrm{NO}_{\mathrm{x}}$. Regulation of MARPOL sets NOx emission limits for installed marine diesel engines. The IMO emissions standards are commonly referred to as Tier I, II and III. The Tier I standards were defined in the 1993 version of Annex VI, while Tier II and III standards were introduced Annex VI amendments adopted in 2008.

Currently, no specific stringency levels hold for NOx emission control areas, but ships constructed on or after 1 January 2016 have to comply with specific standards when operated in the North American ECA or the United States Caribbean Sea ECA (Table 3).

Table 3. IMO $\mathrm{NO}_{\mathrm{x}}$ limits

\begin{tabular}{|c|c|c|c|c|c|}
\hline \multirow[t]{2}{*}{ Tier } & \multirow[t]{2}{*}{$\begin{array}{c}\text { Geographica } \\
\text { I scope }\end{array}$} & \multirow[t]{2}{*}{$\begin{array}{c}\text { Ships } \\
\text { construction } \\
\text { data }\end{array}$} & \multicolumn{3}{|c|}{$\begin{array}{c}\text { Total weighted cycle } \\
\text { emission limit }(\mathrm{g} / \mathrm{kWh}) \\
\mathrm{n}=\text { engine's rated speed } \\
(\mathrm{rpm})\end{array}$} \\
\hline & & & $\mathbf{n}<\mathbf{1 3 0}$ & $\begin{array}{c}n= \\
130-1,999\end{array}$ & $n>\mathbf{2 0 0 0}$ \\
\hline I & Global & $\begin{array}{l}1 \text { January } \\
2000\end{array}$ & 17,0 & $45^{*} n^{-0,2}$ & 9,8 \\
\hline II & Global & $\begin{array}{l}1 \text { January } \\
2011\end{array}$ & 14,4 & $44 * n^{-0,23}$ & 7,7 \\
\hline III & $\begin{array}{c}\text { North } \\
\text { America and } \\
\text { Unites States } \\
\text { Caribbean } \\
\text { Sea } \\
\end{array}$ & $\begin{array}{l}1 \text { January } \\
2016\end{array}$ & 3,4 & $9 * n^{-0,2}$ & 2,0 \\
\hline
\end{tabular}

Source: [10]

The control of engine $\mathrm{NO}_{\mathrm{X}}$ emission is achieved through the survey and certification requirements leading to the issue of an Engine International Air Pollution Preventing Certificate. Different levels of control apply based on the ship construction data and engine's rated speed.

\subsection{New source of energy}

The need to reduce $\mathrm{CO}_{2}$ emissions of the shipping sector in order to deliver maritime contributions for the protection of our environment and to prevent climate change has raised the interest in exploring a number of alternative fuel sources.

$\mathrm{CO}_{2}$ emissions depend on the type of fuel, so the amount of carbon per unit of energy produced. The ability to choose the fuel in the future depends on many factors such as availability, price, durability and regulations and in particular the need to comply with the MARPOL Convention.
Currently, the possibility of using the following energy sources is examined: renewable energy sources such as wind, solar power, second generation biofuels; nuclear propulsion, fuel cells, coal and natural gas.

Renewable energy sources such as wind and solar power, in connection with variable intensity of occurrence, can be used for auxiliary equipment, such as lighting on board ships. Wind and soar conditions differ between regions, so that power is more attractive in certain regions and routes than in others. However, wind and solar power do not provide practically enough power to operate the main engines of vessels (huge physical size of the ship and hence the required power).

First generation biofuels are produced from sugar, starch, vegetable oil, or animal fats. Depending on source, there are certain technical issues, such as stability during storage, acidity, plugging of filters, formation of waxes which may require adapting the engine and selecting the fuels [11].

The new design and construction of engines allow them to operate on some low quality crude vegetable oils, which are considered as the cheapest biofuel available.

The use of liquid biofuel to replace fossil oil in engines carries clear global environmental benefits. Combustion of biofuels results in reduction of greenhouse gases emission and other pollutants, while at the same time allowing for appropriate disposal of waste from biological oils of commercial and industrial origin.

Other arguments in favour of biofuels is the potential for local and regional development, promotion of social and economic cohesion.

First generation biofuels might be considered as possible alternative although there is, considerable public debate about the environmental costs (social effects) of the wider use of such fuels.

Biofuels referred to as second-generation biofuels, produced from residual non-food crops, are considered more sustainable.

Nuclear propulsion for merchant ships is technically possible. Installing nuclear reactor is not taken into account for international shipping due to environmental, political and security reasons.

Fuel cells may be a possibility for new ships in the very long term, although they are currently too limited in range to offer a viable solution.

Coal propulsion is not considered attractive, due to need to remove sulphur oxide emissions, the low thermal efficiency and disposal of the combusted coal residues and ash. Coal could be used as a fuel for steam turbine arrangement.

It is possible to liquid fuels from coal, but emissions of $\mathrm{CO}_{2}$ related to their production are higher than those of petroleum fuel [11].

Liquid natural gas (LNG) produces lower emissions, and could be solution for some short sea trades if supply infrastructure can be developed. In 2015 IMO prepared and developed the text of the International Code of safety for ships using gases or other low flashpoint fuels (IGF Code). The goal of this Code is to provide safe and environmentally-friendly design, construction and operation of ships and in particular their installations of systems for propulsion machinery, auxiliary power 
generation machinery and/or other purpose machinery using gas or low-flashpoint fuel as fuel. The main reason for building vessels fuelled with gas is their environmentally friendly profile both under normal operations and in case of an accident.

Using gas instead of diesel as a fuel is considered beneficial for the environment because of the reduced release of GHG when combusting LNG instead of diesel due to the higher hydrogen to carbon ratio compared to diesel or heavy fuel. The release of $\mathrm{NO}_{\mathrm{X}}$ and particles are reduced significantly $(82 \div 84 \%$ and $67 \%$, respectively). LNG-propelled ships are particularly attractive in emission control areas.

One of the main inconvenience for use of LNG as a fuel for ships is to find sufficient space for the storage of the fuel. In consequence, the potential for reduction of emissions of $\mathrm{CO}_{2}$ through the use of LNG is mainly relevant for new ships.

To better address the needs of marine customers, a system of small-scale and medium-scale terminals with feeder ships bringing LNG from the import terminal to these terminals and bunker ships, etc., must be established. At present, large LNG import terminals exist in the United Kingdom, the Netherlands, and Belgium and additional terminals are likely to be established by 2020 in France, Finland, Germany, Poland, the United Kingdom, and the Baltic countries. These terminals primarily serve to feed into the natural gas grid and cannot be directly used for maritime purposes. An LNG bunkering infrastructure consisting of fixed terminals, bunker ships, tank trucks, etc., should encompass differences in composition as well as capacities.

LNG containers delivered and loaded on the ships to be used as fuel tanks may become an important introductory solution and a complement in a growing maritime LNG market.

Estimates of future fuel prices contain a large number of uncertainties; however, is important if LNG is to be a competitive fuel for shipping.

\section{Conclusion}

Shipping is an essential component of any programme for further sustainable economic growth. It is powerful sector of the global economy making a major contribution to global trade and prosperity and has a relatively negative impact on the environment.

The promotion of sustainable shipping and sustainable maritime development is one of the major priorities of IMO.

The IMO regulations that seek to minimise emissions from ships have a significant beneficial impact on the atmospheric environment and on human health, particularly for coastal communities.

The analysis allows to assume that burning of fossil fuels will remains the primary source of energy for the foreseeable future, and the most significant means of reducing $\mathrm{CO}_{2}$ emission will be achieved by improvements in efficiency across the entire transport chain.
The energy-saving correlated with reduction of emissions $\mathrm{CO}_{2}$ is difficult to assess, as this depends on how efficiently the vessel will be operated.

Achievement of objectives requires also investment in training and motivating the crew, and in monitoring consumption.

The use of biofuels for reducing emissions of $\mathrm{CO}_{2}$ from shipping is limited not only by technological issues but also by cost. The biofuels are, currently, more expensive than petroleum fuels.

LNG is a clean fuel and its price is significantly lower than that of distillate fuels which is creating an economic motivation to use it.

Maritime transport shows significant advantages in carbon emissions when compared to road and air freight. Shifting the mode from track to ship may increase emission from ships, but will have an overall beneficial impact on the emissions from the system for movement of goods as whole.

\section{References}

1. Review of maritime transport, (UNCTAD, Genewa, 2015)

2. T.A. Boden, R.J. Adres, G. Marland, Global, Regional and National Fossil-Fuel CO2 Emissions (CDIAC, Oak Ridge, USA, 2013)

3. G.P. Peters, R.M. Andrew, T. Boden, J.G. Candell, P. Ciais, C. Le Quere, G. Marland, M. R. Raupach, C. Wilson, Nat Clim Chang. 3, 4-6 (2013)

4. Third IMO Greenhouse Gas Study 2014 (IMO, London, 2014)

5. M. Swahn, Measuring transport energy use and emissions (NTM, Sweden, 2009)

6. M.Z., Jacobson, Geophys Res Lett. 27, 217-220 (2000)

7. T.C. Bond, H. Sun, Environ Sci Technol. 39, 59215926 (2005)

8. O. Buhaugh, Second IMO Greenhouse Gas Study 2009 (IMO, London, 2009)

9. Sulphur Oxides $\left(\mathrm{SO}_{\mathrm{x}}\right)$-Regulation 14 (IMO, London, 2014)

10. Nitrogen Oxides $\left(\mathrm{NO}_{\mathrm{x}}\right)$-Regulation 13 (IMO, London, 2014)

11. O.P.R. van Vliet, A.P.C. Faaji, Energ. Convers Manage. 50, 855-876 (2009)

12. D. Vallentin, Energ Policy 36, 2030-2042 (2008) 